\title{
Reciprocal Peer Coaching Supported by a Professional Coach: The Future of Sustained Leader Development?
}

\author{
Liane Kemp \\ Melbourne, Australia
}

\begin{abstract}
Leader development requires learning new ways of behaving, which takes sustained practice over time, yet organizations continue to focus their efforts in traditional classroom style workshops, spending billions of dollars in the process. This paper describes and interrogates a contemporary approach to leader development, that includes reciprocal peer coaching to embed skill development, increase goal attainment, and enable learning transfer into the wider organizational system for positive impact.
\end{abstract}

Keywords: reciprocal peer coaching, leadership development programs, leader development, peer coaching

\section{Introduction}

This paper explores the impact on learning transfer and ongoing behavior change, of embedding a peer coaching component into leadership development programs (LDPs). It offers an approach to sustainable leader development that anecdotally is having a positive impact on both the leaders and the systems in which they operate.

When it comes to developing leaders, much of it is about learning new ways of behaving, literally rewiring the brain (Goleman, Boyatzis \& McKee, 2013; Rock \& Schwartz, 2007), and we know from neuroscience research that it takes on average 66 days of sustained practice to create self-sustaining new neural pathways (Lally, Van Jaarsveld, Potts, \& Wardle, 2010). We also know that adults typically retain just 10 percent of what they hear in classroom lectures, versus nearly two-thirds when they learn by doing (Gurdjian, Halbeisen, \& Lane, 2014), and the little empirical research on the effectiveness of LDPs would tend to support this (Kirchner \& Akdere, 2014).

This paper reports on a case study in which a coach (the author) redesigned and supported the delivery of the coaching component of an LDP in a 
large Australian corporation. It connects the experiences of the coach to a relatively under-theorized context in which peer coaching is anecdotally having a positive impact. A conceptual framework is presented, followed by a description of it in action. I then present my findings and interrogate these through the coaching literature, before offering my conclusions and recommendations.

The LDP discussed in this paper was already established and attended by about 450 of the company's mid-senior level leaders annually. It comprised a three-day residential workshop followed by three 30-minute, one-on-one coaching sessions with a professional coach.

I recommended extending the coaching component to five sessions over five months, based on my experiences of running professional development programs and my understanding that to effect behavior change is a lengthy process that isn't typically addressed in three short coaching sessions. I replaced the 1:1 coaching conversations with peer coaching in triads (or Pods). I also influenced the design of the workshop to align the workshop more closely with the subsequent coaching component. I was one of the external coaches contracted to the program, supporting 65 Pods (178 people). At the time of writing, 30 of those Pods (81 people) had completed the redesigned coaching component.

My evaluation of the program's effectiveness was derived from my own observations of the participants' coaching skills over the five months and from the feedback they offered in the final reflection meeting.

\section{Conceptual Framework}

Parker, Hall, Kram and Wassweman (2018) offer a three-step model for peer coaching: building a strong and trusting relationship between the involved parties; creating success through honing relational practices; and making peer coaching a habit. Their advice echoes the research more broadly and reinforces much of what I discovered during the program that is the subject of this paper.

Parker et al.'s (2018) work is anchored in the social context of peers connecting with peers as a natural consequence of their engagement at work or outside work. By contrast, I offer a model (refer to Figure 1 below) that builds on Parker et al.'s work and ties it to a specific social context: embedding learning and skill transfer following a leader development event (LDE), with 
the aim of positively impacting the leaders in question and the organisation in which they operate.

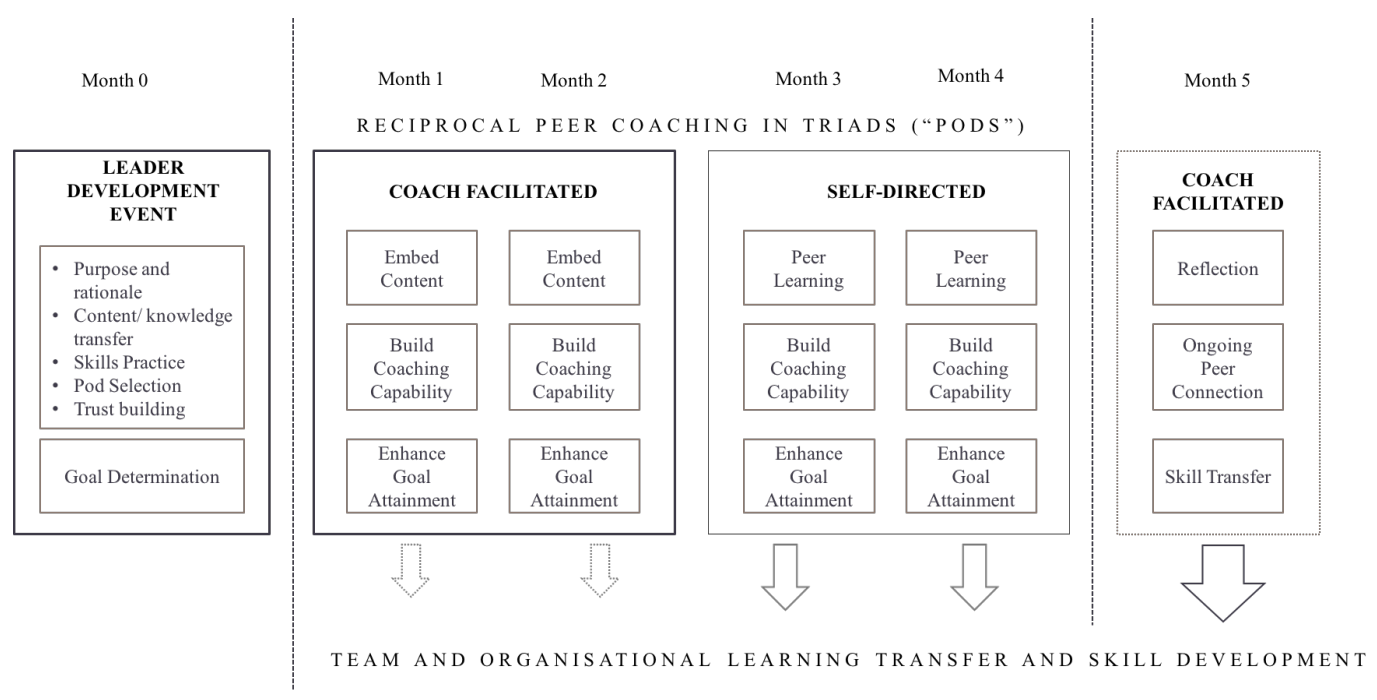

Figure 1. Peer coaching for sustained leader development

\section{Leader Development Event}

The approach described in Figure 1 commences with an LDE that mirrors the best practice design discussed in the literature, including:

- Providing purpose and rationale, namely why leaders should participate and how participation will impact their leadership effectiveness

- Sharing content (at a minimum) on listening, asking questions and a coaching framework

- Developing skills, including practicing with the tools offered.

It also includes activities designed so that participants get to know each other, which helps with selection of Pod colleagues and strengthens trust within the Pods (Step 1 from Parker et al.'s (2018) peer coaching model). Finally, it includes an action learning component - in this case, goal determination, related to their behavior as a leader.

\section{Coach facilitated Pod meetings}

The Pods formed during the LDE comprise three participants. The triad design of the Pods is deliberate; it is a design I have used frequently throughout 
my career in professional development. It offers a mutual learning environment where each role played by the participant (the coach, coachee and observer) provides a unique angle on the learning experience and consequential skill development.

Pod meetings are spread over five months, a time period that allows new habits to be built, reinforced and sustained.

Unlike Parker et al.'s (2018) model, the first two Pod meetings are facilitated by a professional coach. This allows the coach to hone the participants' use of a coaching framework and enhance their questioning and listening skills. During this period, learning transfer into the organisation (via participants sharing with their teams and other important stakeholders) starts, indicated by the size of the arrows at the bottom of the figure above.

\section{Self-directed Pod meetings}

Participants then hold two further Pod meetings without the coach. Continuing to make progress on their goals and enhance their coaching skill is the focus; however, peer learning (sharing ideas) is also a feature of the meetings. Learning transfer into the wider organization is accelerated.

\section{Coach facilitated final Pod meeting}

The final meeting is predominantly a reflection meeting, facilitated by the coach. Ongoing peer connection is re-negotiated (Step 3 from Parker et al.'s (2018) model) and the focus on skill transfer into the wider system is at the forefront.

\section{The conceptual framework in action}

\section{Leader Development Event - Pod selection and trust-building}

The LDE referred to in the case study that is the subject of this paper covered a wide range of topics (including coaching skills and emotional mastery) designed to increase the leadership effectiveness of the participants. While I neither designed, nor facilitated the LDE, I was able to influence its design so that the extended coaching component and the Pod concept were introduced at the outset.

During the workshop, participants selected their Pod colleagues. These Pods met and did 'work' during the workshop, including designing three goals, 
one of which related to their development as a leader. Consequentially, Pod members knew each other coming into the first Pod meeting and had built a relationship during the workshop.

\section{Coach facilitated Pod meetings}

By contrast, I was the outsider, not even an employee of the company. I knew nothing about the participants beyond their names and email addresses. It was therefore important that I built trust and rapport quickly. After a short introduction by each participant, I declared my commitment to confidentiality and then asked them to do the same. Next, I asked each person to share how they were feeling coming into the meeting (a check-in) and modelled what I wanted by displaying a level of vulnerability about my own situation, both professional and personal. This check-in started each Pod meeting and set the tone for the meetings.

In the first Pod meeting I reacquainted the participants with the GROW coaching model that they had been introduced to in the workshop a month before. Knowledge retention was highly variable, as was the percentage of participants who had actively tried to use the model since the workshop. So, in the first Pod meeting I played the role of both coach and teacher by demonstrating the GROW model in action, working with each of the participants, using their chosen leader development goal as the vehicle through which skill development and learning transfer would take place over the ensuing months.

Participants could pick the goal on which they wanted to work, i.e. they set the agenda, as long as it was one that required behavioral change on their part that would enhance their leadership capability. I worked quickly with each participant to clarify the goal, understand the current reality, surface options and reduce these to a small number of actions that the individual would commit to achieving before the second Pod meeting. It was challenging, as I typically had about 20 minutes with each person and topics ranged from issues that were deeply personal to those that were very work focused.

I followed up with the participants a few days after the Pod meeting, encouraging them to email each other and me, summarizing their action commitments. My aim was to keep participants' attention on what they had committed to, thus hopefully increasing the likelihood that they would actually complete their commitments before the next meeting! 
In the second Pod meeting, participants coached each other, and thus reciprocal peer coaching began.

At the end of the second meeting I set up the two self-directed meetings.

\section{Self-directed Pod meetings}

While not involved in the third and fourth Pod meetings, nonetheless I checked in with people ahead of these meetings as a way of continuing to encourage the group to get together.

\section{Coach facilitated final Pod meeting}

It was always gratifying to learn in the final Pod meeting that the majority of the groups had remained connected and continued with the coaching, especially because participation in the Pod coaching was not required to 'complete the program'. The focus of the final meeting was to crystallise participants' insights about their own development both in terms of coaching skillset and goal attainment, and then bring their attention to what they wanted to focus on going forward and how, if at all, their Pod colleagues might help.

\section{Findings}

I collected and analyzed extensive notes or "field texts" (Clandinin \& Connelly, 2000) of each meeting, including the voices of the participants and my own. This study 'emerged' out of my reflection of these notes. I clustered them into the five key themes below. I then turned to the literature in the next section to see if what I was seeing had been reported on by others.

While further empirical studies are required to validate the findings reported below, reflecting on the enactment of the conceptual framework in the context of the LDP, I observed first hand and through the participants' feedback, reciprocal peer coaching supporting leader development and contributing to the participants' ability to embed new skills and transfer their learning into the wider organization.

\section{A non-evaluative, safe, reflective space is critical}

The non-evaluative and safe environment created when peers coached each other, together with a level of trust in the Pod, appeared to be central to the effectiveness of the approach. Although I did not directly measure this, I observed that the Pods in which the members had the strongest connection with 
each other were more likely to stay together over the five months and were more open to giving and receiving feedback.

The check-in process at the start of each meeting, described above, helped reinforce this safe space. I was pleasantly surprised how open people were about their own circumstances, ranging from extraordinary challenges in their personal lives to stressful work situations.

Psychological safety was mentioned regularly by participants during the final Pod meeting, e.g., "It was good to have the conversation with the Pod; I don't trust everyone in my team [peers]. The Pod group was a safe group". Most Pods also agreed that working with peers outside their direct area of the business helped with both safety and also getting a fresh perspective.

The Pod meeting was often referred to as a welcome 'breather' in the craziness of day to day work demands. As one participant said, "The Pod meetings take you out of the bubble, to be on the island for a while. It was good to speak with colleagues and to bounce ideas around helped."

Finally, my role as a professional coach was helpful in terms of trust; this was an organization undergoing massive transformation with many people, including the teams that the participants managed, and in some cases the participants themselves, facing retrenchment. People felt that they could speak freely about the challenges they were facing with their colleagues, with their managers, and with the organization generally, because I wasn't an employee.

\section{Teaching coaching skills helps leaders build capability in their teams, and move from 'telling' to 'asking'}

Moving out of 'solution mode' and from telling to asking was frequently referred to in the final reflection meeting as being the biggest learning and behavioral shift participants made. This participant sums it up well: "Before I would problem solve - usually I would lead the horse, but I have flipped it around. [My team now] present me their proposed approach. I say, "Pretend you are the customer, show me the experience, what would you do? They come to the conclusion on their own. It has led to the upskilling of my team." Another commented, "The biggest learning for me was that previously if someone came to me, I went straight to solutions and fixing the problem. That was my automatic response. I have learned that coaching is about listening, hearing the problem and helping people find their own solution. It has absolutely changed my approach. I now go in with more of a coaching mindset." 
This is where the power of the hybrid approach appeared to help. I modelled coaching in the first Pod meeting. In the second meeting, I reminded the group that when they were coaching, their challenge was to step out of problem-solving mode (which most acknowledged was their default style when coaching their teams). I was aware from the behavioral change literature that 'telling' or 'suggesting' has a negative impact and participants were discovering this too. As one later remarked, "I have moved to 'listener' versus 'answerer'. Staff want to talk; I let them talk versus me telling them. They are failing a lot more, but they are thriving and learning from their mistakes, and I shield them and create a safe place to do that."

Participants had many insights in this second meeting, some from their own reflection, but often from the feedback from the observer and the impact reported by the coachee. As time progressed, it was pleasing to see either the coach catching him/herself asking a leading or a closed question and stopping and reframing the question, or that it only required me to 'stop the action' for the coach to realise what he/she was doing.

\section{Behavioral change and goal attainment is supported}

One of the challenges with making lasting changes to behavior is 'sticking at it' long enough for new habits to take hold (Lally et al., 2010). My hope for the program was that the participants would build a relationship with each other during the first two coach-supervised meetings that would make it more likely for them to continue with the subsequent two self-directed meetings, and ideally engage outside the formal Pod meetings to provide each other support.

The reality bore this out; $83 \%$ of the Pods met at least once, and $70 \%$ had met twice and in a small number of cases the Pods had met more regularly. In the final meeting, almost all said that they wanted to maintain some form of ongoing contact with their Pod colleagues, and in checking in with some of the groups a few months later, I was happy to hear that many had maintained contact.

The framework I provided in the first two Pod meetings brought focus to the self-directed meetings; coaching skills were practiced with progress on goals being the vehicle. There was often good progress on goal attainment following the first meeting, and in cases where there had not been a lot of progress, participants tended to commit to "doing better next time," driven by 
the process (the need to report on progress at each meeting) and their commitment to the other Pod members.

During the second meeting, it was encouraging to see the participants begin to really engage with their colleagues' challenges and, at appropriate times, offering their own insights. In a number of cases, the participants agreed to catch up outside the format of the Pod meetings to brainstorm ideas or rehearse difficult conversations. Thus, not only was peer coaching happening, learning transfer was taking place. Many commented on the value of "bouncing ideas around and getting input from others," versus "being on their own."

In the two self-directed Pod meetings participants tended to continue coaching to help their colleagues with goal attainment. One participant summed it up like this: "I found [the two self-directed meetings] useful. It became increasingly natural the more practice that we did and as we got to know each other. It reinforced the process and rounded it out for me, especially in using open questions. It forces you to check in and I found them to be invaluable."

Not only did the Pod meetings help with achieving goals, the support of the Pod helped drive better outcomes. As one participant said, "I would probably have achieved my goals over time, but it would have taken [me] longer and it helped getting different inputs along the way."

\section{The use of a professional coach is a valuable adjunct to traditional peer coaching}

My role as a professional coach appeared to be important in teaching and modelling for the participants the coaching skills they needed to set them up for success, and for encouraging them to maintain commitment to the program. The following comments from participants describe this well:

- 'Left to our own devices it would've been more challenging; as much as you think you get it, you realize you don't, [the coach's] contribution helped a lot"

- "Two coach-facilitated sessions at the beginning to reinforce the learning was important, it was such a new thing. Practicing it was the key"

- 'It was good to have [the professional coach's experience], it is very easy to fall into the traps, and in the first couple [the coach] helped keep us honest" 
- 'It was helpful having [the professional coach] with us for the first couple [of Pod] meetings, [the coach] got us focused and gave us structure and we followed that same structure [in the self-directed meetings]"

- "Without the first two it wouldn't have been as productive. It would have been more about work."

\section{Leaders grew their own skills and positively impacted the wider organizational system}

Participants reported that the coaching capability they were building through the reciprocal peer coaching was directly impacting the teams they led. As one leader said, "I previously thought I was okay at leadership, I would give my opinion, I would listen to others, and then I would go on with my own opinions. Now I am letting others have their opinion, they take ownership and recently I walked out from a meeting with no action items of my own!" Another added, "I am seeing a shift in my team, e.g. there is one person previously who was always calling, looking for validation, now I have given him the confidence to make decisions and I am seeing the number of calls fall away - he has gained the power to trust himself."

Participants also took these skills into other organizational contexts, including important stakeholders, peers, managers, clients and business partners. One participant noted: "I like to think I've grown as a leader and what I've learned is rubbing off on my peers and my team" and another added that she had noticed her leader interacting with her differently as a result of her engaging with more of a coaching style.

\section{Critical Interrogation of the Findings Through the Literature}

With the backdrop of my experience with the program that is the subject of this paper, I turned to the research to understand how others have embedded skill development on a sustainable basis, increased goal achievement following a LDP, and enabled learning transfer from the leader into the wider organizational system. Specifically, I considered the following questions:

- What is reciprocal peer coaching and what role does it play in leader development?

- What are the criteria for reciprocal peer coaching success? 
- What is the impact of reciprocal peer coaching on the wider organizational system?

\section{What is reciprocal peer coaching and what role does it play in leader development?}

The concept of peer coaching originated in the field of education over 25 years ago as an on-site dimension of staff development. More recently it has been adopted in nursing, and clinical/therapeutic practice (Goldman, Wesner, \& Karnchanomai, 2013; Waddell \& Dunn, 2005; Parker, Wasserman, Kram \& Hall, 2015). Parker et al. (2015) go on to say that in the management and organizational development world, peer coaching is "gaining recognition and respect, given both the positive outcomes and cost-effective aspects reported by individuals and organizations alike" (p. 232).

For the purposes of this paper I have adopted Parker, Hall, and Kram's (2008) definition of peer coaching: "a developmental relationship with the clear purpose of supporting individuals within it to achieve their job objectives ... the interaction is between two or more people with the goal of personal or professional development. The emphasis is on the voluntary, non-evaluative, and mutually beneficial partnership between two [or more] practitioners of similar experience" (p. 490).

Before considering the impact of reciprocal peer coaching on leader development, it is worth defining what constitutes good LDP design. However, one is immediately confronted with a challenge; LDPs are only randomly described and almost never evaluated empirically (Abrell, Rowold, Weibler \& Moenninghoff, 2011; Sørenson, 2017). Kirchner and Akdere (2014), in their search of the literature in the last century, found only 201 studies related to leadership interventions and considerably fewer on whether they were worthwhile. Even though investment in leadership training and development is a more than $\$ 14$ billion industry in the USA (Sørenson, 2017, p. 47), according to Kirchner and Akdere (2014) only "between 10 and 20 percent of organizations investing in LDPs actually follow through to evaluate the program's effectiveness" (p. 144). Ladyshewsky (2017) suggests that transfer into the workplace following training and development initiatives is as low as 15 percent (p. 4).

Kirchner and Akdere (2014) argue that while there is no universal definition, LDPs "emphasize the concerted, formalized effort of individuals and organizations towards leader improvement" (p. 138). Ladyshewsky (2017) and 
Goldman et al., (2013) suggest that LDPs should encompass all four of Conger's (1992) primary approaches:

- Conceptual understanding

- Skill building

- Feedback

- Personal growth

The coaching literature speaks to the positive impact of coaching and providing feedback in leader development (Grant, Curtayne \& Burton, 2009; Thach, 2002; De Haan, Grant, Burger \& Eriksson, 2016); however, coaching interventions to support skill development in the context of LDPs are rarely examined (Abrell et al, 2011) and of particular relevance to this paper, "there is scant literature concerning the use of reciprocal peer coaching in leadership development" (Goldman et al, 2013, p. 63). In addition, where peer coaching is mentioned, it does not include a professional coach as an integral part of the process, thus making the conceptual framework outlined above unique.

\section{What are the criteria for reciprocal peer coaching success?}

Bennett and Bush (2014) tell us that while peer coaches do not need to be expert coaches, they need to have effective listening skills, ask exploratory questions, build trust, and maintain tact, confidentiality and diplomacy. Ladyshewsky's (2017) criteria for success echo the point:

- Status (peers are of equal status)

- Certainty (trust and confidence between peers)

- Autonomy (the coachee determines the agenda)

- Relatedness (the relationship builds positive emotions)

- Fairness (the feedback is non-evaluative, honest and fair)

Status: Equal status helps remove the evaluative aspect of coaching that can arise when the line manager is the coach. Ladyshewsky (2017) suggests that these contexts may not be the safest places to grow professionally and can limit learning "because of the heightened defences that are put into place... activated by parts of the brain's limbic system [in the coachee]" (p. 5). By contrast, "removing the evaluative component [through peer coaching] encourages clients to assess their own strengths and development needs through 
discussion and self-reflection, which builds confidence and commitment" and it also contributes to greater safety in the relationship (Bennett et al., 2014, p. 258). Consistent with the coaching profession, the orientation of the professional coach in the first two Pod meetings is one of equal status, focused on the coachee as a whole person with the inherent skills to build their own capability.

While Parker et al. (2015) also speak to the equality in the relationship, the lack of power dynamics, and a relational process, they include the absence of a professionally trained coach as a distinguishing characteristic (p. 232). By contrast, the model outlined in this paper advocates the use of a professional coach. The coach is present only for the first two sessions to set the participants up for success, especially in providing tools around questioning, listening, and a coaching framework, and in providing feedback on their practice. Feedback from participants suggests that this approach adds value over and above what they would gain on their own.

Certainty: Ladyshewsky (2017), Goldman et al. (2013), Parker et al. (2008, 2015) and Waddell and Dunn (2005) all talk about the centrality of trust in peer coaching, created through peer coaches getting to know each other at the outset, building rapport, mutual respect and exploring their background experiences. In the LDP described, participants selected their own Pod colleagues and did work together during the workshop. In the coaching component, the professional coach, having made a commitment to the Pod not to share the content of the meetings, contributes to this sense of psychological safety, as do the "check ins" at the start of each meeting.

Listening and asking non-evaluative questions also helps build trust (Goldman et al., 2013; Parker et al., 2015). Participants found this the most challenging part of the peer coaching process, because the natural tendency is to want to help or provide advice. However, as Ladyshewsky (2017) points out, this changes the status and makes the coach an evaluator and consultant (p. 8). In the first Pod meeting the professional coach teaches and models best practices in listening and questioning through the lens of the GROW framework; participants' skills are honed during practice in the second Pod meeting.

Autonomy: Increasing autonomy is supported by having the participants pick the goal on which they want to work, i.e. they set the agenda (Waddell \& Dunn, 2005). Choosing their own goal also increases their commitment. As Grant et al. (2009) report, "commitment to self-set goals tends to be higher than 
commitment to goals set by other people" (p. 404). In the first two meetings, the coach provides feedback and strategies to the peer coaches when they attempt to take over the agenda and 'drive the conversation.'

Relatedness: The mainstream executive coaching literature suggests that the quality of the relationship between coach and coachee mediates success (McGovern, Lindemann, Vergara, Murphy, Barker, \& Warrenfeltz, 2001; De Haan et al., 2016). Passmore, Peterson, and Freire (2013), quoting Stober and Grant (2006), suggest that "regardless of preferred theoretical perspective, the foundation of effective coaching is the successful formation of a collaborative relationship" (p. 47). The peer coaching model described supports relatedness; participants get to select their own peer coaches, the relationship is strengthened in the first two Pod meetings through the coach demonstrating empathy and asking (and helping others ask) curious questions, and then it is carried through into the self-directed Pod meetings.

Fairness: The format of the practice rounds in the Pod meetings contains a feedback process. Feedback is frequently mentioned in the literature as having a positive impact on leader development. Thach (2002) suggests that the combination of feedback and coaching can increase leadership effectiveness by up to 60 percent (p. 209). However, the manner in which the feedback is provided is a critical determinant. Groves (2006) asserts that one-on-one follow up meetings with facilitators to help people interpret their behavioral feedback is much more effective than simply producing a feedback report (p. 255). Selfassessment is also a valuable component (Waddell \& Dunn 2005). The peer coaching format described incorporates these findings; the professional coach sets the process for and models giving feedback in the first two meetings, to ensure that the feedback is honest and offered with a developmental focus. Peer coaches are asked to comment on their own coaching first (self-assessment), followed by feedback from the coachee and finally the observer. The professional coach adds feedback at the end. Interestingly, it is often the feedback provided by the coachee that creates 'lightbulb moments' for the peer coach.

Finally, Bennett et al. (2014) and Waddell and Dunn (2005) also recommend the need for some form of education about how to coach and a framework to keep the client clear on the goals. The GROW coaching framework is taught during the initial workshop, but the learning is embedded through modelling and the provision of feedback by the coach in the first two Pod meetings. 


\section{What is the impact of reciprocal peer coaching on the wider organizational system?}

Bennett et al. (2014) state that "peer coaching has been shown to accelerate group or organisational change and create a self-sustaining coaching organisation" (p. 263). However, there are very few examples in the literature that speak to the impact of peer coaching in embedding skills and enabling learning transfer into the wider organisational system following a LDP in medium to large corporations. Bennett et al. (2014) comment on case studies at Citizen's Financial Group and CocaCola Enterprises, both of which showed the use of peer coaching as a component of larger LDPs ultimately supported a culture of learning and development (p. 260).

Abrell et al. (2011) reported on a study designed by Rowold (2008) that provided initial evidence that peer to peer coaching led to increased transfer of learned content after training in the German branch of an international drug company. Ladyshewsky (2017) talks of his own research where "it is clear that peer coaching can enhance the professional development and performance of individuals across a broad range of sectors" (p. 6) and he cites specific examples in physical therapy students, universities and a "large [Australian] government agency."

Although not set in a large corporation, Goldman et al.'s (2013) study conducted amongst students undertaking a faculty medical education fellowship program of the George Washington University is noteworthy because it uses a control group, comparing the impact of a LDP with and without peer coaching. "Analysis of the data indicated that the coaching cohort completed or was on schedule for completion of $73 \%$ of their planned initiatives, compared to $50 \%$ for the standard cohort. Having the structured process of support-reciprocal peer coaching, journaling, and interview-discussions - was credited by the participants as making the difference" (p. 80).

Finally, Parker et al. (2015) suggest that with experience of peer coaching participants "are consciously or even unconsciously competent in processes that lead to high-quality connections, and they will tend to naturally peer coach on their own, without being prompted by a third party" (p. 237).

\section{Recommendations and concluding comments}

The anecdotal data from this preliminary study (a combination of the observations of the author and the feedback from the participants) tends to 
suggest that when peer coaching is used as an integral part of a LDP and when a professional coach facilitates the first couple of meetings, it supports the individual to achieve their goals and learn new skills. Although it couldn't be validated directly in this preliminary study, there is emerging support that the individuals in the program were also taking the coaching skills they learned in order to coach their peers, and applying them in multiple organizational contexts with positive outcomes, an impact that they reported continuing to see five months after the end of the LDP. This is an area worthy of further research.

Based on the findings garnered from 81 participants across 30 Pods, I recommend organisations contemplating leader development consider adopting the conceptual model outlined in this paper and pay special attention to the items below:

\section{For organizations designing LDPs}

- Ensure that the LDE provides participants with a coaching framework and content related to staying out of judgement/problem-solving, together with skill building on listening and asking powerful questions

- Add a peer coaching component following the LDE to provide the vehicle for skill practice. As participants commented, "You spend so much time in the three-day workshop, but the real value is in the practice in your day-to-day activities. Without the Pod meetings to remind you, and a space for reflection, it would not have been so valuable"

- Use "real work" (the participants' goals) as the vehicle for learning and to assist with goal attainment

- Ensure that the peer coaching period is long enough to embed the behaviors being practiced. "For me it speaks to the importance of time you can't change overnight - the six-month period is critical"

- Use a professional coach to facilitate the first couple of peer coaching sessions to set the participants up for success

- Expand the understanding of what best practice leadership development looks like and measure the impact of LDPs on the individual and the wider organisational system. 


\section{For coaches supporting LDPs}

- Provide a safe ongoing supportive environment. As another participant said, "You go to the workshop, link arms and sing Kumbaya. But afterwards when you need the support, no one is there. So, the workshop on its own is not necessarily the answer. The Pod meetings helped me maintain the changes I wanted to make"

- Model for the participants how to use the coaching framework and how listening and asking powerful questions helps avoid the tendency to go to problem-solving/advice giving.

\section{Limitations of this study}

This preliminary study arose from the experiences of the author in supporting the LDP in question. The findings appear to be supported by the literature. However, the study lacks a rigorous method to quantify the findings, especially over the longer term.

The challenge for the academy is to undertake quantitative and longitudinal studies to support the findings reported here and determine the long-term impact of the recommendations provided. Such studies would ideally include a control group and in addition to reflections in the final meeting, contain 'self' and 'other' assessment of the leaders immediately before and after the LDP and again six months later. The early findings on organisational impact could be investigated through a similar 'self' and 'other' assessment (pre- and post-LDP) of the teams who report to the LDP participants.

\section{References}

Abrell, C., Rowold, J., Weibler, J., \& Moenninghoff, M. (2011). Evaluation of a long-term transformational leadership development program. German Journal of Human Resource Management, 25(3), 205-224. https://doi.org/10.1177/239700221102500307

Bennett, J. L., \& Bush, M. W. (2013). Coaching for change. Routledge. https://doi.org/10.4324/9780203140970

Clandinin, D. J., \& Connelly, F. M. (2000). Narrative inquiry: Experience and story in qualitative research. San Francisco: Jossey Bass Publishers.

de Haan, E., Grant, A. M., Burger, Y., \& Eriksson, P. O. (2016). A large-scale study of executive and workplace coaching: The relative contributions of relationship, personality match, and self-efficacy. Consulting 
Psychology Journal: Practice and Research, 68(3), 189.

https://psycnet.apa.org/doi/10.1037/cpb0000058

Goldman, E., Wesner, M., \& Karnchanomai, O. (2013). Reciprocal peer coaching: A critical contributor to implementing individual leadership plans. Human Resource Development Quarterly, 24(1), 63-87. https://doi.org/10.1002/hrdq.21153

Goleman, D., Boyatzis, R. E., \& McKee, A. (2013). Primal leadership: Unleashing the power of emotional intelligence. Boston, Mass.: Harvard Business Press.

Grant, A. M., Curtayne, L., \& Burton, G. (2009). Executive coaching enhances goal attainment, resilience and workplace well-being: A randomised controlled study. The journal of positive psychology, 4(5), 396-407. https://doi.org/10.1080/17439760902992456

Groves, K. S. (2007). Integrating leadership development and succession planning best practices. Journal of management development, 26(3), 239-260. https://doi.org/10.1108/02621710710732146

Gurdjian, P., Halbeisen, T., \& Lane, K. (2014). Why leadership-development programs fail. McKinsey Quarterly, 1(1), 121-126.

Kirchner, M. J., \& Akdere, M. (2014). Leadership Development Programs: An Integrated Review of Literature. The Journal of Knowledge Economy \& Knowledge Management IX Spring.

Ladyshewsky, R. K. (2007). A strategic approach for integrating theory to practice in leadership development. Leadership \& Organization Development Journal, 28(5), 426-443. https://doi.org/10.1108/01437730710761733

Ladyshewsky, R. K. (2017). Peer coaching as a strategy to increase learning and development in organisational life-a perspective. International Journal of Evidence Based Coaching and Mentoring, 15(1), 4-10.

Lally, P., Van Jaarsveld, C. H., Potts, H. W., \& Wardle, J. (2010). How are habits formed: Modelling habit formation in the real world. European journal of social psychology, 40(6), 998-1009. https://doi.org/10.1002/ejsp.674

McGovern, J., Lindemann, M., Vergara, M., Murphy, S., Barker, L., Warrenfeltz, R., \& Warrenfeltz, R. (2001). Maximizing the impact of executive coaching. The Manchester Review, 6(1), 1-9.

Parker, P., Hall, D. T., \& Kram, K. E. (2008). Peer coaching: A relational process for accelerating career learning. Academy of Management Learning \& Education, 7(4), 487-503. https://doi.org/10.5465/amle.2008.35882189 
Parker, P., Wasserman, I., Kram, K. E., \& Hall, D. T. (2015). A relational communication approach to peer coaching. The Journal of Applied Behavioral Science, 51(2), 231-252. https://doi.org/10.1177\%2F0021886315573270

Parker, P., Hall, D. T. T., Kram, K. E., \& Wasserman, I. C. (2018). Peer Coaching at Work: Principles and Practices. Stanford, CA: Stanford University Press.

Passmore, J., Peterson, D., \& Freire, T. (2016). The Wiley-Blackwell handbook of the psychology of coaching and mentoring. Hoboken, NJ: John Wiley $\&$ Sons.

Rock, D., \& Schwartz, J. (2007). The neuroscience of leadership. Reclaiming children and youth, 16(3), 10-17.

Sørensen, P. (2017). What research on learning transfer can teach about improving the impact of leadership-development initiatives. Consulting Psychology Journal: Practice and Research, 69(1), 47-62. https://psycnet.apa.org/doi/10.1037/cpb0000072

Thach, E. C. (2002). The impact of executive coaching and 360 feedback on leadership effectiveness. Leadership \& Organization Development Journal, 23(4), 205-214. https://doi.org/10.1108/01437730210429070

Waddell, D. L., \& Dunn, N. (2005). Peer coaching: the next step in staff development. The Journal of Continuing Education in Nursing, 36(2), 84-89. https://doi.org/10.3928/0022-0124-20050301-09

\section{Author Contact}

The author, Liane Kemp, of Kemp Street Partners Pty Ltd, can be contacted via email at 1kemp@kempstreetpartners.com.au. 